\title{
Vulnerability of a specialised pollination mechanism to climate change revealed by a 356-year analysis
}

Michael J. Hutchings ${ }^{1}$, Karen M. Robbirt ${ }^{2,3}$, David L. Roberts ${ }^{4}$ \& Anthony J. Davy ${ }^{2}$

1 School of Life Sciences, University of Sussex, Falmer, Brighton, Sussex, BN1 9QG, UK 2 Centre for Ecology, Evolution and Conservation, School of Biological Sciences, University of East Anglia, Norwich Research Park, Norwich, NR4 7TJ, UK

3 Royal Botanic Gardens, Kew, Surrey TW9 3AB, UK

4 Durrell Institute of Conservation and Ecology, School of Anthropology and Conservation, Marlowe Building, University of Kent, Canterbury, Kent CT2 7NR, UK

Corresponding author: Michael J. Hutchings, School of Life Sciences, University of Sussex, Falmer, Brighton, Sussex, BN1 9QG, UK. Tel: 01273 557999. Email:

M.J.Hutchings@sussex.ac.uk

Running head: Climate change risk to pollination mechanism 


\begin{abstract}
Pollination of Ophrys sphegodes by sexual deception of male Andrena nigroaenea bees depends both on male bees emerging before female bees and before flowering, and on the orchid flowering before female bee emergence, so that competition for the services of naïve male bees is avoided. Using previously-established relationships between the timing of these phenological events and spring temperature, we model flowering and bee emergence dates from 1659-2014, using Central England Temperature records. All phenological events were predicted to advance significantly over this period, accompanying a trend towards warmer springs. The interval between male and female flight decreased over time, whereas that between male flight and flowering increased. In addition, female flight preceded orchid flowering after warm springs, and it preceded both flowering and male bee flight following the warmest springs. Such reversals in phenology have increased in frequency over the last 356 years. In most years, the Ophrys/Andrena pollination system achieves very limited pollination success. The results presented here suggest that climate warming has changed the timing of the phenological events that are critical to reproductive success in O. sphegodes, and that continuing warming will increase the frequency of years in which this rare orchid suffers complete reproductive failure.
\end{abstract}

Keywords: Andrena nigroaenea, Central England Temperature record, climate change, Ophrys sphegodes, herbarium specimens, natural history collections, phenology 


\section{Introduction}

Weather conditions in any year and long-term climate change both affect the timing of important events in the annual life cycles of many species. Temperature in particular exerts a strong influence on phenology, but the strength of its influence can differ significantly between species (Fitter et al., 1995; Sparks, Jeffree \& Jeffree, 2000; Kauserud et al., 2008 Crimmins, Crimmins \& Bertelsen, 2010; Iler et al., 2013). It is widely speculated (Memmott et al., 2007; Heglund et al., 2009; Kharouba \& Vellend, 2015) that phenological shifts caused by climate change pose a significant threat to ecological relationships in which one species depends on another, such as those between plants and their pollinators. If flowering time and the dates on which pollinators are active diverge in response to long-term climate warming, pollination could be reduced, or fail completely.

Species with highly specialised pollination mechanisms are likely to be especially vulnerable to loss of synchrony with their pollinators. For many species in the family Orchidaceae, pollination is so specialised that it can only be achieved by one species (Tremblay, 1992) or a small group of closely-related species, and many orchid species with such specialised pollination systems are already rare and endangered. Although some are capable of self-pollination, any reduction in cross-pollination will increase their risk of local and global extinction (Tremblay 1994; Tremblay et al., 2005). For such species, annual temperature variations could have a critical effect on pollination success by altering the relative timing of flowering and pollinator activity, and longer-term climate change could progressively reduce the probability of pollination. Evidence for such effects might be especially clear in orchids with highly specialised pollination systems, and would strongly support the contention that climate change will disrupt relationships between co-dependent species. 
One of the most comprehensive analyses to date of the potential for climate change to disrupt phenological synchrony in a specialised plant-pollinator relationship involves the early spider orchid, Ophrys sphegodes Mill., and the solitary mining bee Andrena nigroaenea, which is its sole pollinator in the United Kingdom (Robbirt et al., 2011, 2014; see also Willmer, 2014). O. sphegodes reaches its northern range limit in the UK. It has suffered a severe range contraction in the United Kingdom since records began, although limited recovery has been achieved more recently (Jacquemyn \& Hutchings, 2015). Whereas Wigginton (1999) classified O. sphegodes as near-threatened in the UK, it is now categorised as of Least Concern (Cheffings \& Farrell, 2005). Nevertheless, its range in the UK is at least $60 \%$ smaller than it was in 1930 (Jacquemyn \& Hutchings, 2015). Several causes for this decline have been identified, including habitat destruction and the transitory nature of suitable habitat, unsuitable grazing regimes, a low rate of establishment from seed, a very short life-span and infrequent vegetative propagation (Hutchings, 2010). Pollination is also very inefficient. Ripe O. sphegodes fruits can contain 5000-10,000 seeds (Soliva \& Widmer, 2003), but as few as $5 \%$ of flowers are visited by pollinators in some populations (Ayasse et al., 2000). The percentage of flowers producing fruits is usually well below $25 \%$, and no more than $20 \%$ of plants produce fruits (Delpino, in Darwin, 1877; Lang, 1980; Neiland \& Wilcox, 1998; Gay \& Philp, 1999; Vandewoestijne et al., 2009). Establishment from seed is very low in most years (Hutchings, 2010). If long-term climate change is altering the time between flowering in $O$. sphegodes and the flying time of its pollinator, or changing the sequence of these events, the current low reproductive success of the orchid may be exacerbated, increasing the threat to its survival.

Management regimes have been proposed to reverse declines in $O$. sphegodes populations (Hutchings, 2010), but the potential threats to its reproduction due to annual variations in weather conditions and long-term climate change on pollination success have 
not been taken into account. This study examines the effects of long-term changes in temperature on divergence between the phenology of flight in Andrena nigroaenea and flowering in Ophrys sphegodes. Understanding the ways in which the relative timing of these events is changing over the long term is important, not only because it may explain the low levels of pollination in $O$. sphegodes, but because it may also indicate whether long-term climate warming threatens the survival of this rare species.

Ophrys sphegodes flowers emit a floral bouquet that strongly resembles that of virgin female Andrena nigroaenea (Schiestl et al., 1997, 1999, 2000), leading to sexual deception of naïve male bees. In most years, male A. nigroaenea emerge before peak flowering in $O$. sphegodes. In common with many bee species (Eickwort \& Ginsberg, 1980), the emergence of male $A$. nigroaenea also usually precedes the emergence of females, and in the temporary absence of female bees to mate with, the males attempt to copulate with flowers of the orchid. In doing so, they transfer pollen from one flower to another. Male bees quickly become habituated to the floral bouquet. Because the orchid provides no reward for the pollinator, there is no incentive for habituated bees to continue to visit orchid flowers, but variation in the chemical signature of the floral bouquet between plants (Borg-Karlson, 1990; Schiestl et al., 1997, 1999, 2000), and between visited and unvisited flowers (Schiestl \& Ayasse, 2001), may result in more mating attempts with unvisited flowers. However, as the floral bouquet is only emitted when flowers are fresh (Nieland \& Wilcock, 1995; Jacquemyn \& Hutchings, 2015), pollinators are only attracted for a short period.

Pollination in $O$. sphegodes is strongly dependent on the temporal sequence of bee emergence and orchid flowering. Success depends on male bees emerging from winter hibernation before orchid flowering and female bee emergence, and on the orchid flowering before female bee emergence. Crucially, if flowering and female bee emergence coincide, or if female bees emerge earlier than the orchid flowers, pollination is likely to be reduced or 
even fail completely, because of competition between the orchid and female bees for, respectively, pseudocopulatory and copulatory services from male bees. Temporal separation of male and female bee emergence, and of orchid flowering and female bee emergence, is therefore vital even for the limited pollination success that is usually achieved. Robbirt et al., (2014) found that yearly variation in spring temperature had markedly different impacts on the phenology of flight in male and female Andrena nigroaenea, and of flowering in Ophrys sphegodes. For several reasons this may have serious consequences for pollination success. Firstly, these differences will cause the time that elapses between each of these phenological events to be dependent on the weather in any year. This may determine whether female bees are in flight at the same time as the orchid is in flower, and therefore affect the length of time for which male bees will pseudocopulate with orchid flowers. Secondly, climate change could lead to long-term increases or decreases in the mean number of days between each of these events. Thirdly, the sequence in which these events occur may change between years, and the frequency of such differences in sequence might alter as warmer springs become more common. Finally, female bee emergence coinciding with, or preceding, orchid flowering in any year, and especially in sequences of consecutive years, would be potentially disastrous for orchid pollination, and for the survival of this short-lived orchid species, both locally and globally.

Robbirt et al., (2014) used several long-term datasets to quantify the effects of variation in temperature between years on the phenology of flowering in Ophrys sphegodes and emergence in Andrena nigroaenea. We now use the relationships established in that study to model dates of flowering and bee emergence for every year from 1659-2014, using the Central England Temperature (CET) record. We then address the following questions: (i) is there variation in the sequence of the three phenological events (flowering in O. sphegodes and emergence of male and female bees of A. nigroaenea) between years during this 356- 
year period, and if so, is the frequency of such differences changing? (ii) is there evidence for changes in the time elapsing between each of the three phenological events? (iii) does this system provide evidence that climate change can adversely affect critical inter-species dependencies?

\section{Material and methods}

Four sets of long-term data were used to examine the effects of temperature on the relationships between the timing of flowering in Ophrys sphegodes and the emergence of male and female Andrena nigroaenea, as follows: (i) Data on mean monthly temperature from 1659 to 2014 were obtained from the Central England Temperature (CET) record (http://hadobs.metoffice.com/hadcet/cetml1659on.dat). (ii) Data on timing of flowering in $O$. sphegodes were obtained from a field-based demographic study conducted from 1975 to 2006 (Hutchings 1987a,b, 2010) in which population censuses were carried out at the peak of flowering in each year. Information on the timing of data collection was available for 25 out of 32 years of the study. (iii) Data on peak flowering of $O$. sphegodes between 1848 and 1958 were obtained from fully dated herbarium specimens stored at the Royal Botanic Gardens, Kew, and the British Museum, London. To ensure that only plants collected at the peak of flowering were included in the study, specimens with less than $60 \%$ of their flowers open were discarded (Robbirt et al., 2011). A total of 77 specimens was available for use in the analysis. (iv) Peak flying dates of male and female $A$. nigroaenea were obtained from fully dated museum specimens held at the Natural History Museum, London, and Oxford University Museum of Natural History. In total, 357 specimens were included in the analysis (208 male specimens collected between 1893 and 2004, and 149 female specimens collected between 1900 and 2007), with at least one specimen collected in each of 81 years within a 115-year period from 1893 to 2007. Although specimens could have been collected at any 
time in the flying season, on average over the 115 years the dates of collection would tend to represent peak flying dates (Robbirt et al. 2014).

Analysis of the effects of weather variables (mean temperature, total rainfall and total sunshine hours calculated over various time periods prior to flowering, and number of frost days in the winter prior to flowering) on peak flowering date in Ophrys sphegodes have shown that spring temperatures and, to a lesser extent, number of frosts, have significant impacts on peak flowering date, whereas rainfall does not (Hutchings, 2010). Furthermore, no significant effect of rainfall on flowering date was discernible in the herbarium data Robbirt (2012). The timing of emergence of many bee species is also significantly affected by spring temperature (Bartomeus et al., 2011), whereas rainfall is less likely to exert a strong influence on this phenological event (Robbirt, 2012). Moreover, many bees, including species in the genus Andrena, exhibit protandrous emergence, suggesting different physiological responses to temperature in male and female bees (Eickwort \& Ginsberg, 1980; Baldock, 2008). This background informed our decision to examine the effects of spring temperatures on the timing of emergence of Andrena nigroaenea and peak flowering of Ophrys sphegodes over the 356-year period of the CET record.

Regressions of mean annual temperature and mean spring (March-May) temperature against year were calculated from the CET temperature record to seek evidence of long-term warming, both at an annual level and within the spring months that most strongly influenced the timing of bee flight and orchid flowering. Bartomeus et al., (2011) reported accelerated warming in North American temperature records from 1970 onwards compared with the rate of warming between 1900 and 2010. To seek corroboration of this finding, we examined the relationship between temperature and year of recording from 1970-2014, and then compared the gradients of the regressions calculated over the periods 1659-2014 and 1970-2014. 
Linear regression relationships established by Robbirt et al., (2014) between peak flying dates of male and female $A$. nigroaenea, peak flowering dates in O. sphegodes, and spring temperature (Table 1), were used to predict the dates on which each of these events occurred in each of the 356 years of the CET record. (Polynomial regressions only produced marginal increases in $\mathrm{r}^{2}$, and the absence of a plausible biological rationale for such relationships did not justify their use.) The relationship between flowering date and spring temperature had been extensively validated using two independent sets of data: herbarium records and field observations (Robbirt et al., 2011). The trend of earlier bee flying date with increasing spring temperature had also been validated, by comparing the museum records with the extremely large dataset of the Bees, Wasps \& Ants Recording Society (BWARS), although the latter did not allow analysis by bee gender (Robbirt et al., 2014). Mean temperature from March May was the best predictor of peak flying date of female bees and of peak flowering date in O. sphegodes, whereas mean temperature from February - April was the best predictor of peak flying date of male bees. For every $1{ }^{\circ} \mathrm{C}$ rise in spring temperature, peak flying date of male $A$. nigroaenea advanced by 9.2 days, that of female bees advanced by 15.6 days, and peak flowering date of $O$. sphegodes advanced by 6.4 days (Robbirt et al., 2014). Linear regressions, using the appropriate spring temperature, were calculated to quantify long-term change in the predicted dates of peak flying and peak flowering between the start and end of the whole CET recording period, and between 1970 and 2014. The gradients of regressions between these two periods were compared to seek evidence of accelerating changes in the timing of these events.

In addition, comparisons were made of the regression gradients with time between each pair of phenological events over the period 1659-2014. Significant differences between these gradients, even in the face of potentially wide variation in spring temperature between individual years, would be strong evidence of systematic changes in the time elapsing 
between pairs of phenological events over the 356-year temperature record. Quantification of the time elapsing between each of the three events was obtained by dividing the 356 -year temperature record into seven "eras", each approximately 50 years in duration (1659-1710, $1711-1760,1761-1810,1811-1860,1861-1910,1911-1960$ and 1961-2014). For each of the seven eras, we calculated the mean number of days predicted to have elapsed between each pair of phenological events. Significant changes in the mean length of time elapsing between each pair of events across the seven eras were sought using analysis of variance.

Finally, evidence was sought for changes in the sequence of the three phenological events (peak flying date of male and female bees and peak orchid flowering date) over the 356-year temperature record. It was assumed that successful pollination of the orchid requires (i) that male bee peak flying date precedes orchid peak flowering date and female bee peak flying date, and (ii) that orchid peak flowering date precedes female bee peak flying date. The proportion of years in which this order of events was fulfilled by the predicted dates of bee flight and orchid flowering was calculated for each of the seven eras.

\section{Results}

Both mean annual temperature and mean spring (March - May) temperature, calculated from the CET dataset, demonstrate significant warming from 1659 to 2014 (Fig. 1a, b). The relationships imply an increase in mean annual temperature from $8.79{ }^{\circ} \mathrm{C}$ to 9.74 ${ }^{\circ} \mathrm{C}$ and an increase in mean spring temperature from $7.68{ }^{\circ} \mathrm{C}$ to $8.64{ }^{\circ} \mathrm{C}$ during this 356 -year period. The mean rate of warming, as indicated by both the mean annual temperature and mean March-May temperature, was significantly faster between 1970 and 2014 than over the whole period from 1659 to 2014 ( $P=0.0066$ and 0.0025 respectively).

Peak flying dates for male and female bees, and orchid peak flowering date, all showed significant advancement from 1659 to 2014 (all $P<0.0001$, Fig. S1a-c). The 
regressions predict advances in peak flying dates for male and female Andrena nigroaenea of 10.51 and 15.09 days respectively, and an advance in peak flowering for Ophrys sphegodes of 6.21 days over this period. The rates of change in phenology were all significantly faster between 1970 and 2014 than they were over the whole of the CET recording period $(P=$ 0.0025 for all comparisons).

The average time between peak flying date of male and female Andrena nigroaenea was predicted to have fallen between 1659 and 2014 from 6.51 days to 1.93 days (Fig. 2a). In contrast, the time elapsing between male bee peak flying date and peak flowering of $O$. sphegodes was predicted to have increased from 5.04 days to 9.37 days (Fig. 2b). Whereas predicted peak flying date of female bees was slightly later (1.48 days) than peak orchid flowering at the start of the CET recording period, the regression indicates that female bees are now likely to achieve peak flying date 7.43 days earlier than orchid flowering reaches its peak (Fig. 2c). The changes in the number of days elapsing between the predicted dates of each pair of phenological events were significant across the 356-year period, i.e. the regression gradients were all significantly different from zero (male bee flying time - female bee flying time, $r=-0.16, P<0.01$; male bee flying time - orchid flowering time, $r=0.19, P$ $<0.001$; female bee flying time - orchid flowering time, $r=-0.32, P<0.0001, n=354$ in all cases).

Phenological predictions from the seven 50-year eras from 1659-2014 showed that in years with warmer springs, female $A$. nigroaenea reached peak flying date earlier than males, and that the frequency of years in which this happened was lower before the beginning of the twentieth century (Fig. 3a). The data also show that although male A. nigroaenea usually reach peak flying date before the peak of flowering in O. sphegodes, this is not always the case (Fig. 3b). Since the start of the eighteenth century, peak orchid flowering has preceded peak male bee flying date in $10-20 \%$ of years, but $350-300$ years ago, when spring 
temperatures were usually lower than they have been more recently, peak flowering preceded male bee peak flying date in approximately $35 \%$ of years. As spring temperatures have risen, the frequency of years in which the predicted female bee peak flying date preceded peak flowering in O. sphegodes has increased almost uninterruptedly. Peak flying date of female A. nigroaenea preceded peak flowering in O. sphegodes in $80 \%$ of the years from 1961 to 2014, whereas this only occurred in $40 \%$ of the years between 1659 and 1710 (Fig. 3c).

There were significant changes in the predicted mean number of days elapsing between each pair of phenological events across the seven eras into which the data were divided (Fig. 3d-f). There was a rapid and almost continuous reduction in mean time between peak flying dates of male and female A. nigroaenea (Fig. 3d). In contrast, the time between male bee peak flying date and peak flowering in $O$. sphegodes increased significantly from the first era to the last (Fig. 3e). The mean date of female bee emergence has been earlier than that of peak flowering in all eras since the beginning of the eighteenth century, and the time between these events has been steadily increasing. Peak flying date of female bees was, on average, approximately 8 days earlier than peak orchid flowering between 1961 and 2014, whereas mean peak flowering preceded female bee peak flying date by approximately 2 days between 1659 and 1710 (Fig. 3f). The data indicate that female $A$. nigroaenea peak flying date preceded peak flowering in O. sphegodes in 26 of the last 28 years, and in 17 of the last 18 years.

\section{Discussion}

The sensitivity to temperature of both the flowering date of Ophrys sphegodes and the flying date of Andrena nigroaenea (Robbirt et al., 2011, 2014) is typical of many kinds of phenological change that can be attributed to climatic warming, where spring and summer events are advanced by warmer springs (see e.g. Thackeray et al., 2010). Robbirt et al., 
(2014) have suggested that the disparity of responses to temperature between $O$. sphegodes and its specialist pollinator has the potential to threaten the synchrony required for effective pollination by sexual deception. This is similar in principle to postulated mismatches between insects and specialist nectar providers arising from different rates of phenological advancement in response to spring warming (Forrest \& Thompson, 2011; Kudo, 2014; Kharouba \& Velland, 2015). In contrast, generalist pollinators may provide sufficient phenological overlap to insure community-wide pollination services against warmer years (Memmott et al., 2007; Forrest \& Thompson, 2011; Iler et al., 2013). For example, Bartomeus et al., (2011) showed that, from 1880 to 2010, ten bee species emerged earlier, and the advance was significant in four species. Significant differences between advances in bee emergence and plant flowering were not observed however, suggesting that climate change was not causing phenological divergence. Bartomeus et al., (2011) acknowledged that their approach limited the likelihood of observing divergence because it compared the combined responses of ten bee species to the combined responses of large numbers of plant species, and they emphasized the need for studies comparing phenological responses to temperature in plant species and the specific pollinators on which they depend (see also Gezon, Inouye \& Irwin, 2016). The current study addresses this requirement, in a system that is perhaps especially sensitive because the plant species is close to its northern range limit.

Although Bartomeus et al., (2011) found no significant differences in the phenological responses to temperature of males and females of ten North American bee species, the large number of bee species described as having protandrous emergence (Eickwort \& Ginsberg, 1980), including Andrena species (Baldock, 2008), clearly suggests that male and female physiologies differ in their responses to temperature. There is a clear difference in phenological response to temperature between male and female $A$. nigroaenea (Robbirt et al., 2014), but its full consequences only become apparent when these responses 
are modelled against the long-term temperature record utilised here (King et al., 2015). Warmer springs produced a greater advance in peak flying date for female bees than for males, and peak orchid flowering date advanced less than either of these events, providing further evidence of differences in metabolic responses to temperature between autotrophic and heterotrophic organisms (Brown et al., 2004). The combination of these divergent responses has the potential to cause catastrophic damage to pollination in Ophrys sphegodes because of long-term changes in the intervals between all three phenological events as spring temperatures have increased (Fig. 4). The time between male bee peak flying date and orchid flowering was shorter at the start of the temperature record than it is now, whereas the time between male and female bee peak flying dates was longer. The change in relative timing of orchid flowering and female bee flying date is more complex. Herbarium and museum specimens were available to provide information on flowering and flight times back to the mid- and late-nineteenth centuries respectively. From these dates until the present, there has been significant change in the time elapsing between these events. On average, female flight has preceded flowering, and the time between these events has increased (Fig. 3f), as has the proportion of years in which female flight has been predicted to precede flowering (Fig. 3c). Predictions for the years before herbarium and museum specimens were available suggest that female flight date has been on average slightly earlier than flowering date from early in the eighteenth century (see also Fig. 4). However, even before then there were many years in which spring temperature was high enough for female bees to be in flight before the orchid flowered. In the most recent eras examined here, spring temperatures have been warm enough for female emergence to precede flowering in most years. Unless the orchid undergoes rapid selection for earlier flowering following warm springs, it is therefore likely that continued climate change will result in it always flowering after the emergence of female bees. 
It is probable that populations of Ophrys sphegodes contain genetic variation on which adaptive evolution might act to at least partially overcome the predicted changes in the order of phenological events. This is suggested by the fact that different plants within $O$. sphegodes populations reach peak flowering on different dates over a 3-4 week period. Some of this variation may be caused by microclimatic effects, but differences in genotype are also likely to be involved. Although the date of peak female Andrena nigroaenea emergence is advancing faster than that of peak flowering in $O$. sphegodes, any plants that flower before the emergence of female bees may still be able to benefit from pseudocopulation, whereas later-flowering plants probably could not. Genotypes conferring early flowering would therefore be selected if warming progresses continuously. However, the long-term warming trend is accompanied by wide and unpredictable yearly fluctuations in climatic variables, including temperature (Fig. 1). Consequently, the strength - and even the direction - of selection on flowering date may vary strongly between years, and this is likely to disrupt selection for earlier flowering. As A. nigroaenea does not appear to benefit from the relationship with $O$. sphegodes, it is unlikely that the bee will be subject to directional selection favouring the maintenance of pseudocopulation. Overall, therefore, it is doubtful whether adaptive evolution will prevent temperature-driven changes in phenology from affecting pollination in $O$. sphegodes.

Although male Andrena nigroaenea usually emerge before Ophrys sphegodes flowers, our results suggest that this is not always the case, and that it has not been since at least the mid-seventeenth century. Between 1659 and 1710, when springs were cooler, the orchid is predicted to have flowered before male bees emerged in approximately $35 \%$ of years. In years with springs cool enough for this to happen, it is possible that, even though Ophrys flowers may attract pollinators for a few days (Nieland \& Wilcock, 1995), the first flowers to open might not be cross-pollinated before they wither, due to the absence of male 
bees. Under such circumstances, seeds could only be produced autogamously. While autogamy has been observed in other Ophrys species (Claessens \& Kleynen, 20011), it has not been reported in $O$. sphegodes, and Vandewoestijne et al., (2009) state that $O$. sphegodes is allogamous. In more recent years, with higher spring temperatures causing greater advance in male bee emergence than orchid flowering, there appear to have been fewer years in which flowering has preceded male bee flight. A continuation of climate warming will lead to years in which orchids flower before male bees emerge becoming ever less frequent. If the success of the sexual deception depended only on male bee emergence preceding orchid flowering, and not also on the timing of female bee emergence, these warming-induced changes in phenology would enable pseudocopulation to occur in a higher proportion of years.

Reversal in the sequence of female bee emergence and flowering is likely to have grave consequences for orchid pollination. If female bees are flying when the orchid is flowering, or even before it flowers (Fig. 4), male bees will be drawn to copulate with them instead of pseudocopulating with the orchid. It has been reported that the fragrance signal emitted by flowers of Ophrys exaltata - a close relative of $O$. sphegodes - is even more attractive to male bees of its pollinator, Colletes cunicularius, than the odour emitted by female C. cunicularius (Vereeken \& Schiestl, 2008). We are unaware of published evidence for a comparable situation in the $O$. sphegodes/A. nigroaenea pollination system, but even if similar circumstances obtained, the orchid would have to compete with female Andrena nigroaenea for the services of male bees in any year warm enough to allow female bee emergence to coincide with, or precede, orchid flowering. This would be likely to reduce orchid pollination, and possibly prevent it entirely. Our results suggest that, even 350-300 years ago, there was often a very short window of time between orchid flowering and female bee emergence (Fig. 4). Even a very short window for pseudocopulation would have been absent in most of the years for which herbarium, field and museum data sources were 
available. The data indicate that female bees emerged before the orchid flowered in 26 of the 28 years prior to 2014 (Fig. 3c), suggesting that few of these years favoured pseudocopulation. Long sequences of years in which pollination is severely limited, or fails completely, will be disastrous in the long term because $O$. sphegodes plants have a half-life of only 2.25 years following emergence from their subterranean phase of life, and multiplication by vegetative propagation is infrequent (Hutchings, 2010). Regular recruitment from seed to replace dying individuals is therefore essential to maintain populations. Although mature seed capsules can contain up to 10,000 seeds (Soliva \& Widmer, 2003), establishment from seed, and survival of recruits to sexual maturity, are very low (Hutchings, 2010). As climate warming continues, it appears that years in which orchid flowering precedes female bee emergence will become ever less frequent, resulting in fewer years in which seeds are produced, and smaller seed crops in each of those years.

Although A. nigroaenea is considered protandrous (Baldock, 2008; i.e. males emerge from hibernation before females), our data suggest that, even in the earliest era of the CET data, there were years in which spring temperatures were warm enough for female bees to emerge much earlier than males (Fig. 3a). This was predicted to have occurred in $20-30 \%$ of years in most of the eras we examined, but approximately 100 years ago the frequency of such years appears to have increased (Fig. 3b). Female bees were predicted to have emerged before males in approximately half of the last fifty years. Female bees are only sexually receptive for a short time following emergence (Paxton \& Tengo, 2001), and therefore egg production could be reduced or fail completely in years with very warm springs, when male bees might not emerge until near the end of this brief period of receptivity, or until after it has closed. Even though A. nigroaenea is common and widespread in the UK, this could have detrimental consequences for its populations, and further reduce the effectiveness of the $O$. sphegodes/A. nigroaenea pollination system. 
There are as yet few documented examples of deleterious effects on fitness caused by loss of phenological synchrony between species with different temperature sensitivities. However, it has been shown that in warmer years there is a shorter interval between the arrival of migratory broad-tailed hummingbirds at their northern breeding grounds and the first flowering of their vital nectar sources (McKinney et al., 2012), and Kudo \& Ida (2013) reported that early onset of spring in a series of years advanced flowering in Corydalis ambigua populations more than the activity of their pollinating bumblebees, leading to lower seed-set. Our results suggest that the $O$. sphegodes/A. nigroaenea pollination system, which is already inefficient, will become even less effective as climate warming continues, mainly because of the increased likelihood of female bee peak flying date preceding orchid peak flowering date (Fig. 4). Ultimately, hand pollination may be necessary as a conservation measure for $O$. sphegodes, particularly near the northern limit of its range in the UK, both because climate warming will cause its pollinator to pay less attention to the sexual deception practised by the orchid, and because the pollinator itself may become less abundant. Hand pollination has already been advocated by Phillips et al. (2015) to conserve another orchid, Caladenia huegelii, with a single pollinator species (a thynnid wasp) which is already rare.

Our results strongly support the widely expressed view that climate change threatens ecological interactions in which critical stages in the annual life cycle of one species depend on coinciding with the timing of particular stages in another. Phenological divergence caused by species responding differently both to annual weather fluctuations and to climate warming, as in the case of $O$. sphegodes and A. nigroaenea, clearly has the potential to disrupt such relationships. Further studies are now urgently required to assess the potential for phenological change, caused by climate warming, to cause widespread community disruption. 


\section{Acknowledgements}

We thank Mark Spencer and David Notton at the Natural History Museum (British Museum) and James Hogan at the Oxford University Museum of Natural History for access to the botanical and entomological collections. The Bees, Ants and Wasps Recording Society (BWARS) very kindly provided access to their extensive observational field data of Andrena. We are grateful to three reviewers for valuable comments. K.M.R. was funded by the Swiss Orchid Foundation and Royal Botanic Gardens, Kew. 


\section{References}

Ayasse M, Schiestl FP, Paulus HF, Löfstedt C, Hansson B, Ibarra F \& Francke W 2000. Evolution of reproductive strategies in the sexually deceptive orchid Ophrys sphegodes: how does flower-specific variation of odor signals influence reproductive success? Evolution 54: 1995-2006.

Baldock DW 2008. Bees of Surrey. Woking, Surrey Wildlife Trust.

Bartomeus I, Ascher JS, Wagner D, Ascher JS, Wagner D, Danforth BN, Colla S, Kornbluth S \& Winfree R 2011. Climate-associated phenological advances in bee pollinators and bee-pollinated plants. Proceedings of the National Academy of Sciences, USA 108: 20645-20649.

Borg-Karlson A-K 1990. Chemical and ethological studies of pollination in the genus Ophrys (Orchidaceae). Phytochemistry 29: 1359-1387.

Brown JH, Gillooly JF, Allen AP, Savage VM \& West GB 2004. Toward a metabolic theory of ecology. Ecology 85: 1771-1789.

Claessens J. \& Kleynen J. 2011. The Flower of the European Orchid. Form and Function. Amsterdam: Schrijen-Lippertz, Voerendaal/Stein.

Crimmins TM, Crimmins MA \& Bertelsen CD 2010. Complex responses to climate drivers in onset of spring flowering across a semi-arid elevation gradient. Journal of Ecology 98: 1042-1051.

Eickwort GC \& Ginsberg HS 1980. Foraging and mating behavior in Apoidea. Annual Review of Entomology 25: 421-446.

Fitter AH, Fitter RSR, Harris ITB \& Williamson MH 1995. Relationship between flowering date and temperature in the flora of a locality in central England. Functional Ecology 9: 55-60. 
Forrest JRK \& Thompson JD 2012. An examination of synchrony between insect emergence and flowering in Rocky Mountain meadows. Ecological Monographs 81: 469-491.

Gezon ZJ, Inouye DW \& Irwin RE 2016. Phenological change in a spring ephemeral: implications for pollination and plant reproduction. Global Change Biology 22: 17791793.

Hegland SJ, Nielsen A, Lázaro A, Bjerknes A-L, \& Totland Ø. 2009. How does climate warming affect plant-pollinator interactions? Ecology Letters 12: 184-195.

Hutchings MJ 1987a. The population biology of the early spider orchid, Ophrys sphegodes Mill. I. A demographic study from 1975-1984. Journal of Ecology 75: 711-727.

Hutchings MJ 1987b. The population biology of the early spider orchid, Ophrys sphegodes Mill. II. The temporal behaviour of plants. Journal of Ecology 75: 729-742.

Hutchings MJ 2010. The population biology of the early spider orchid Ophrys sphegodes Mill. III. Demography over three decades. Journal of Ecology 98: 867-878.

Iler AM, Inouye DW, Høye TT, Miller-Rushing AJ, Burkle LA \& Johnston EB 2013. Maintenance of temporal synchrony between syrphid flies and floral resources despite differential phenological responses to climate. Global Change Biology 19: $2348-2359$.

Jacquemyn H \& Hutchings MJ 2015. Biological Flora of the British Isles: Ophrys sphegodes. Journal of Ecology 103: 1680-1696.

Kauserud H, Stige LC, Vik JO, Økland RH, Høiland K \& Stenseth NC 2008. Mushroom fruiting and climate change. Proceedings of the National Academy of Sciences, USA 105: 3811-3814. 
Kharouba HM \& Vellend M 2015. Flowering time of butterfly nectar food plants is more sensitive to temperature than the timing of butterfly adult flight. Journal of Animal Ecology 84: 1311-1321.

King AD, Oldenborgh GJ, Karoly DJ, Lewis SC \& Cullen H 2015. Attribution of the record high Central England temperature of 2014 to anthropogenic influences. Environmental Research Letters 10: 054002.

Kudo G 2014. Vulnerability of phenological synchrony between plants and pollinators in an alpine system. Ecological Research 29: 571-581.

Kudo G \& Ida TY 2013. Early onset of spring increases the phenological mismatch between plants and pollinators. Ecology 94: 2311-2320.

\section{McKinney AM, CaraDona PJ, Inouye DW, Barr B, Bertelsen CD \& Waser NM 2012.} Asynchronous changes in phenology of migrating Broad-tailed Hummingbirds and their early-season nectar resources. Ecology 93: 1987-1993.

Memmott J, Craze PG, Waser NM \& Price MV 2007. Global warming and the disruption of plant-pollinator interactions. Ecology Letters 10: 710-717.

Nieland MRM \& Wilcock CC 1995. Maximisation of reproductive success by European Orchidaceae under conditions of infrequent pollination. Protoplasma 187: 39-48.

Paxton RJ \& Tengo J 2001. Doubly duped males: the sweet and the sour of the orchid's bouquet. Trends in Ecology and Evolution 16: 167-169.

\section{Phillips RD, Peakall R, Retter BA, Montgomery K, Menz MHM, Davis BJ, Hayes C,} Brown GR, Swarts ND \& Dixon KW 2015. Pollinator rarity as a threat to a plant with a specialized pollination system. Botanical Journal of the Linnean Society 179: 511525. 
Robbirt KM 2012. Phenological responses of British orchids and their pollinators to climate change: an assessment using herbarium and museum collections. Norwich: $\mathrm{PhD}$ thesis, University of East Anglia.

Robbirt KM, Davy AJ, Hutchings MJ \& Roberts, DL 2011. Validation of biological collections as a source of phenological data for use in climate change studies: a case study with the orchid Ophrys sphegodes. Journal of Ecology 99: 235-241.

Robbirt KM, Roberts DL, Hutchings MJ, \& Davy AJ 2014. Potential disruption of pollination in a sexually deceptive orchid by climatic change. Current Biology 24: 2845-2849.

Schiestl FP \& Ayasse M 2001. Post-pollination emission of a repellent compound in a sexually deceptive orchid: a new mechanism for maximizing reproductive success? Oecologia 126: 531-534.

Schiestl FP, Ayasse M, Paulus HF, Erdmann D \& Francke W 1997. Variation of floral scent emission and postpollination changes in individual flowers of Ophrys sphegodes subsp. sphegodes. Journal of Chemical Ecology 23: 2881-2895.

\section{Schiestl FP, Ayasse M, Paulus HF, Löfstedt C, Hansson BS, Ibarra F \& Francke W.} 1999. Orchid pollination by sexual swindle. Nature 399: 421-422.

\section{Schiestl FP, Ayasse M, Paulus HF, Löfstedt C, Hansson BS, Ibarra F \& Francke W.} 2000. Sex pheromone mimicry in the early spider orchid (Ophrys sphegodes): patterns of hydrocarbons as the key mechanism for pollination by sexual deception. Journal of Comparative Physiology, Series A 186: 567-574.

Soliva M, Kocyan A \& Widmer A 2001. Molecular phylogenetics of the sexually deceptive orchid genus Ophrys (Orchidaceae) based on nuclear and chloroplast DNA sequences. Molecular Phylogeny and Evolution 20: 78-88. 
Sparks TH, Jeffree EP \& Jeffree CE 2000. An examination of the relationship between flowering times and temperature at the national level using long-term phenological records from the UK. International Journal of Biometeorology 44: 82-87.

Thackeray SJ, Sparks TH, Frederiksen M, Burthe S, Bacon PJ, Bell JR, Botham MS, Brereton TM, Bright PW, Carvalho L, Clutton-Brock T, Dawson A, Edwards M, Elliott JM, Harrington R, Johns D, Jones ID, Jones JT, Leech DI, Roy DB, Scott WA, Smith M, Smithers RJ, Winfield IJ \& Wanless S 2010. Trophic level asynchrony in rates of phenological change for marine, freshwater and terrestrial environments. Global Change Biology 16: 3304-3313.

Tremblay RL 1992. Trends in pollination biology of the Orchidaceae: evolution and systematics. Canadian Journal of Botany 70: 642-650.

Tremblay RL 1994. Frequency and consequences of multi-parental pollinations in a population of Cypripedium calceolus L. var. pubescens (Orchidaceae). Lindleyana 9: 161-167.

Tremblay RL, Ackerman JD, Zimmerman JA \& Calvo R 2005. Variation in sexual reproduction in orchids and its evolutionary consequences: a spasmodic journey to diversification. Biological Journal of the Linnean Society 84: 1-54.

Vandewoestine SR, Rois AS, Caperta A, Baguette M \& Tyteca D 2009. Effects of individual and population parameters on reproductive success in three sexually deceptive orchid species. Plant Biology 11: 454-463.

Vereeken NJ \& Schiestl FP 2008. The evolution of imperfect floral mimicry. Proceedings of the National Academy of Sciences, USA 105: 7484-7488.

Willmer P 2014. Climate change: bees and orchids lose touch. Current Biology 24: R1133R1135. 
Table 1. Established relationships between peak flying dates for male and female Andrena nigroaenea and peak flowering date for Ophrys sphegodes, and mean spring temperature. For male bees, $x_{\mathrm{FA}}$ is mean temperature over the months from February to April. For female bees and for orchid flowering, $x_{\mathrm{MM}}$ is mean temperature over the months from March to May. $y$ is time, in days after March 1, for peak flying date or peak flowering date to be reached. See Robbirt et al., (2014) for further details.

$$
r^{2} \quad P \quad \text { d.f. }
$$

Male bee flying date

$$
y=122.8-9.168 x_{\mathrm{FA}}
$$

0.157

$<0.0001$

208

Female bee flying date

$$
y=202.3-15.640 x_{\mathrm{MM}}
$$

$0.167<0.0001$

149

Orchid peak flowering date

$y=130.0-6.423 x_{\mathrm{MM}}$

$0.230<0.0001$ 
Fig. 1. (a) Mean annual monthly temperature, and (b) mean monthly temperature from March to May, calculated from the Central England Temperature (CET) record from 1659 to 2014. Mean annual monthly temperature $v s$ years from 1659-2014 (open and closed circles), $y=$ $4.3788+0.00266 x, \mathrm{r}=0.4102, \mathrm{r}^{2}=0.1683, P=<0.0001, \mathrm{n}=354$, and from 1970-2014 (open circles), $y=-34.18+0.02 x, r=0.526, r^{2}=0.277, P<0.0001, \mathrm{n}=44$. Mean monthly temperature from March to May vs. years from 1659-2014 (open and closed circles), $y=$ $3.1660+0.00272 x, \mathrm{r}=0.3153, \mathrm{r}^{2}=0.0994, P<0.0001, \mathrm{n}=354$, and from 1970-2014 (open circles), $y=--56.62+0.03 x, r=0.505, r^{2}=0.255, P<0.0001, \mathrm{n}=44$.

Fig. 2. Time (days) between (a) predicted male and female Andrena nigroaenea flying dates between 1659 and $2014\left(y=27.915-0.013 x, r=0.162, r^{2}=0.026, P<0.0001, \mathrm{n}=354\right),(\mathrm{b})$ predicted male Andrena nigroaenea flying date and peak flowering date in Ophrys sphegodes between 1659 and $2014\left(y=-15.204+0.012 x, r=0.187, r^{2}=0.035, P<0.0001, \mathrm{n}=354\right),(\mathrm{c})$ predicted female Andrena nigroaenea flying date and peak flowering date in Ophrys sphegodes between 1659 and $2014\left(y=43.119-0.025 x, r=0.315, r^{2}=0.099, P<0.0001, \mathrm{n}=\right.$ 354). Positive values on the y-axis indicate that the timing of the first-mentioned phenological event preceded that of the second.

Fig. 3. Proportion of years in each of seven 50-year eras (see text) during which (a) peak flying date of male Andrena nigroaenea was predicted to precede peak flowering date of female Andrena nigroaenea, (b) peak flying date of male Andrena nigroaenea was predicted to precede peak flowering date in Ophrys sphegodes, (c) peak flying date of female Andrena nigroaenea was predicted to precede peak flowering date in Ophrys sphegodes, (d) mean number of days predicted to elapse between peak flying date of male Andrena nigroaenea and female Andrena nigroaenea $\left(F_{6,349}=8.12, P<<0.001\right)$, (e) peak flying date of male 
Andrena nigroaenea and peak flowering date in Ophrys sphegodes $\left(F_{6,349}=8.08, P<<0.001\right)$, (f) peak flying date of male Andrena nigroaenea and peak flowering date in Ophrys sphegodes $\left(F_{6,349}=8.08, P<<0.001\right)$.

Fig. 4. Schematic diagram of the predicted changes in timing of flight in male (black) and female (red) Andrena nigroaenea, and flowering (green) in Ophrys sphegodes between Era 1 $(1659-1710)$ and Era $7(1961-2014)$. All three phenological events are earlier in May in Era 7 than in Era 1 because of climate warming, but warming has the greatest impact on timing of female bee emergence and the smallest effect on timing of orchid flowering. The gradients and positions of the lines shown for each phenological event are based on the predicted effects of temperature. The time elapsing between each pair of phenological events shows gradual changes in response to warming, and the predicted sequence of the three events changes from Era 1 to Era 7. In Era 1, the mean timing of male flight precedes that of orchid flowering, which in turn (just) precedes that of female flight. In Era 7, however, male flight (just) precedes female flight, and female flight precedes orchid flowering by several days. 
Fig. 1a

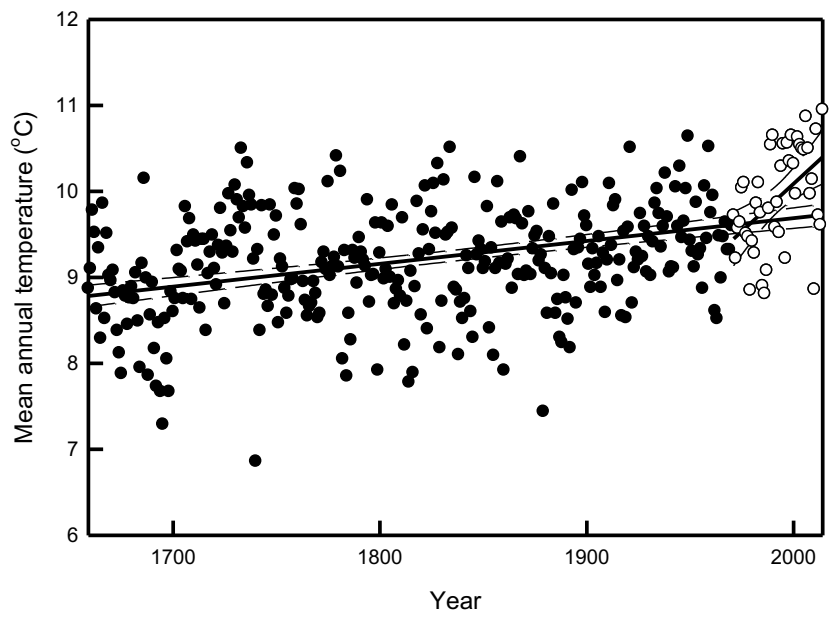

Fig. 1b

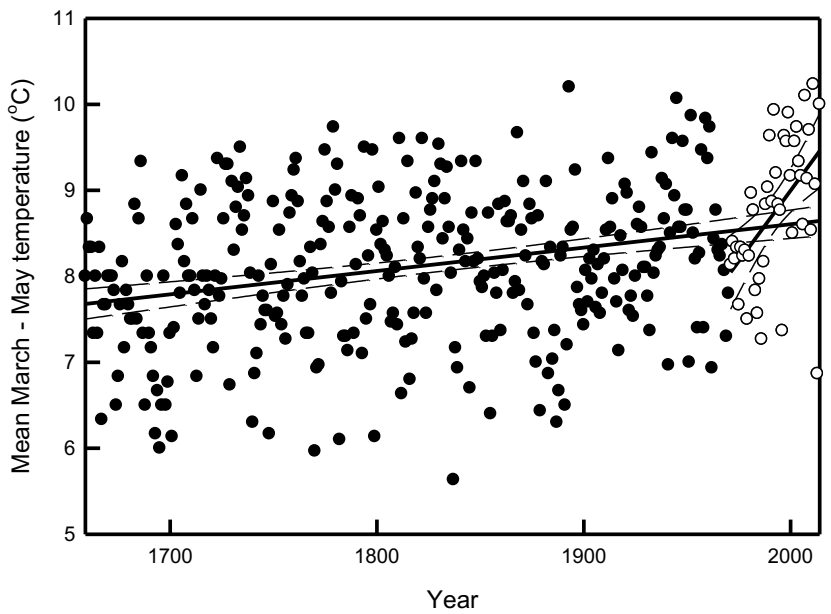


Fig. 2a

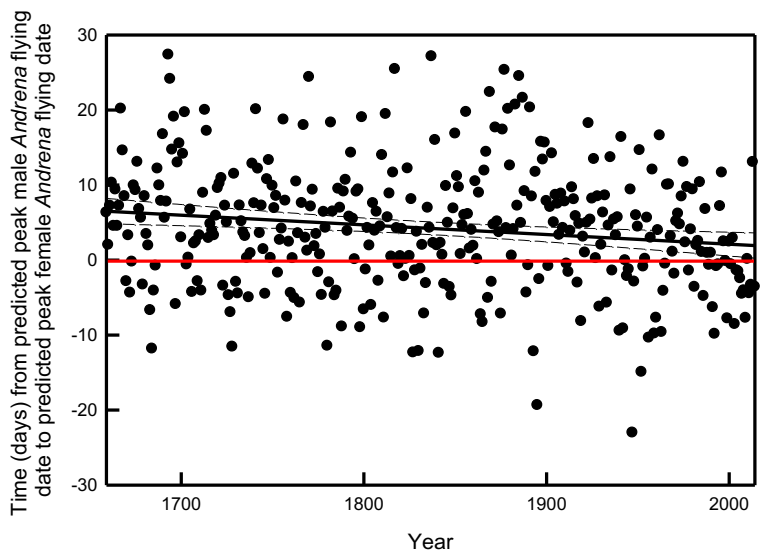

Fig. 2b

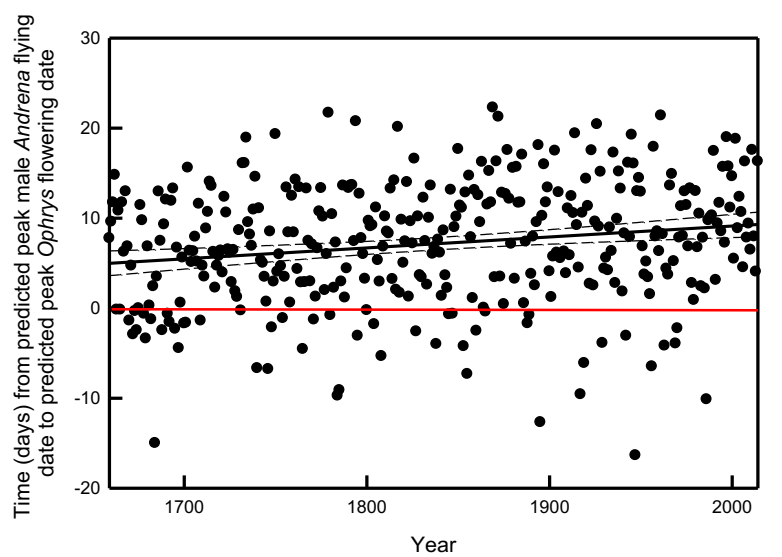

Fig. 2c

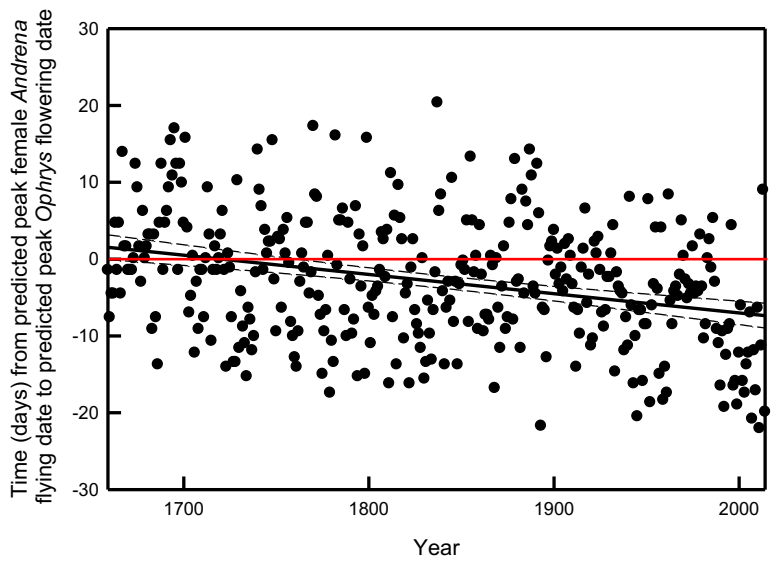


Fig. 3a

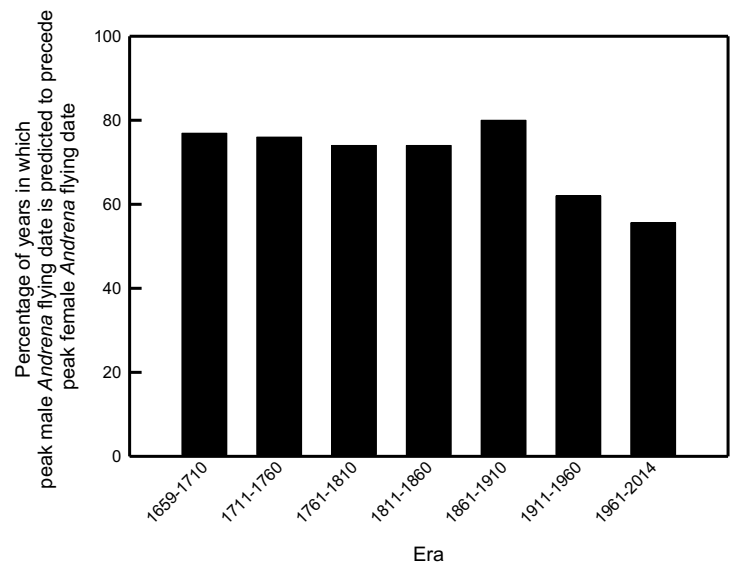

Fig. 3b

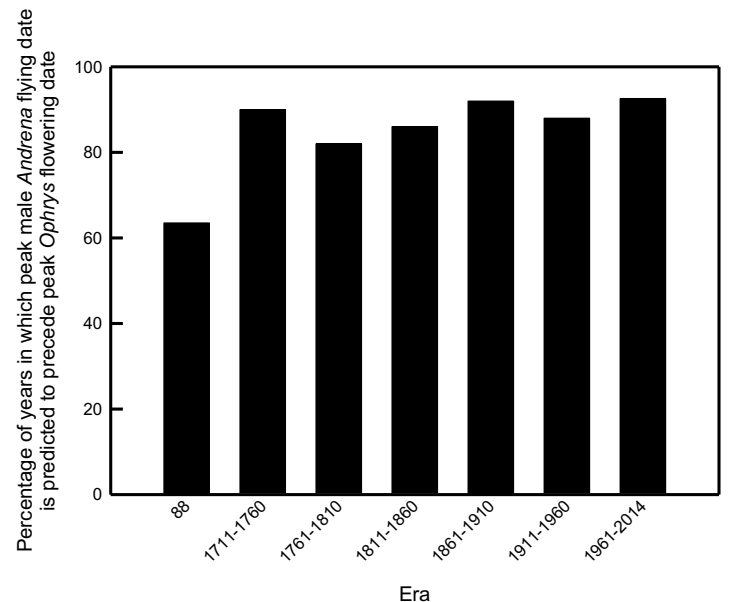

Fig. 3c

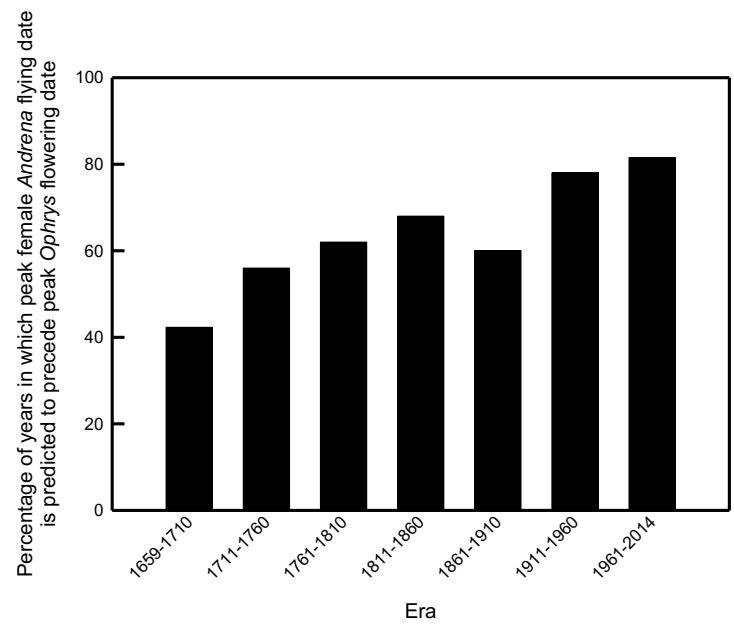

Fig. 3d

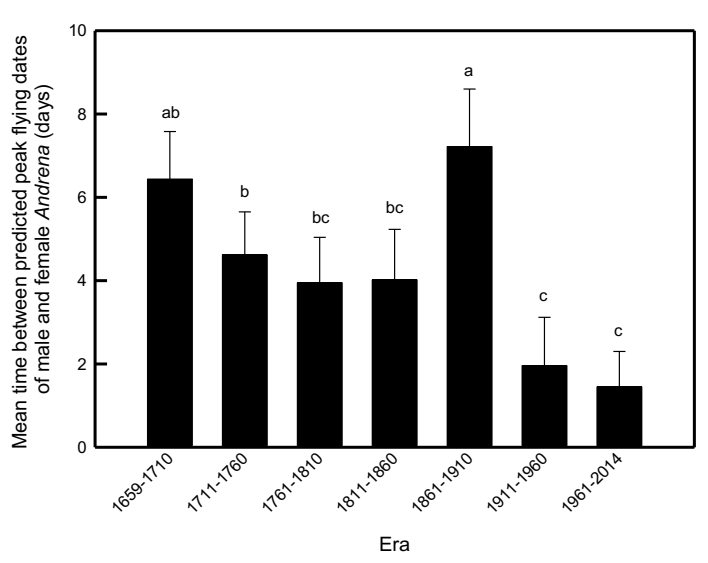

Fig. 3e

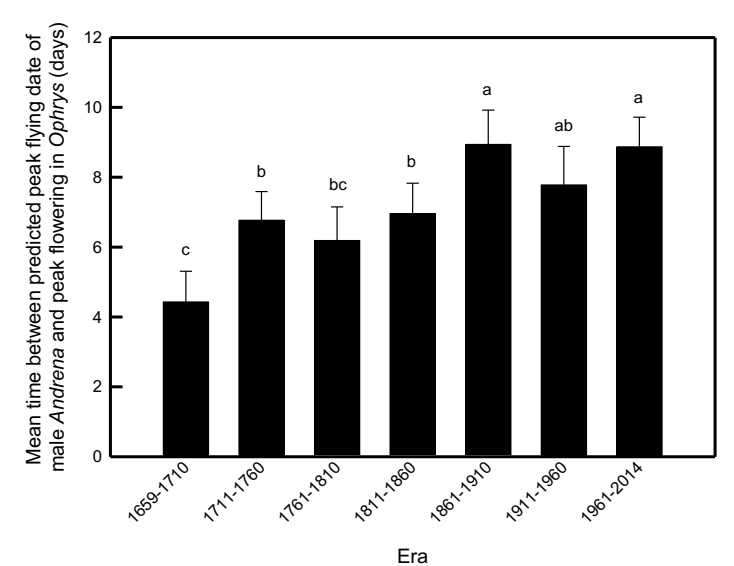

Fig. 3f

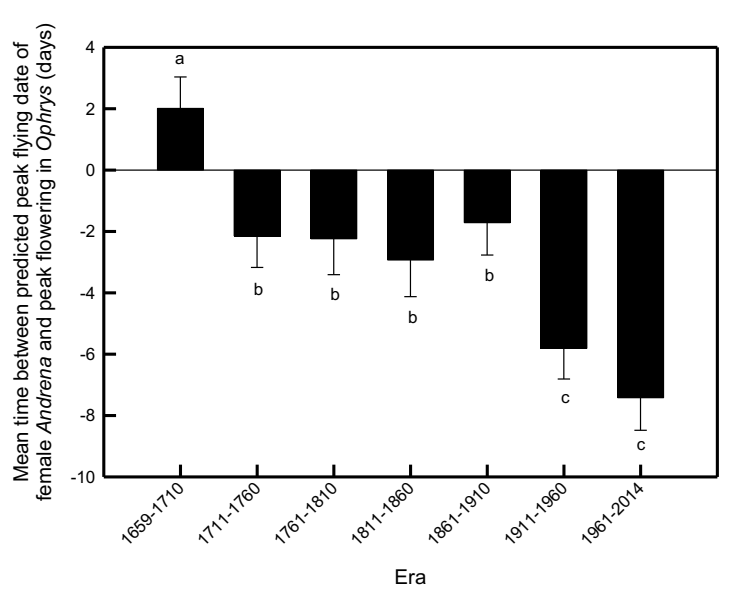


Era 1

Era 7

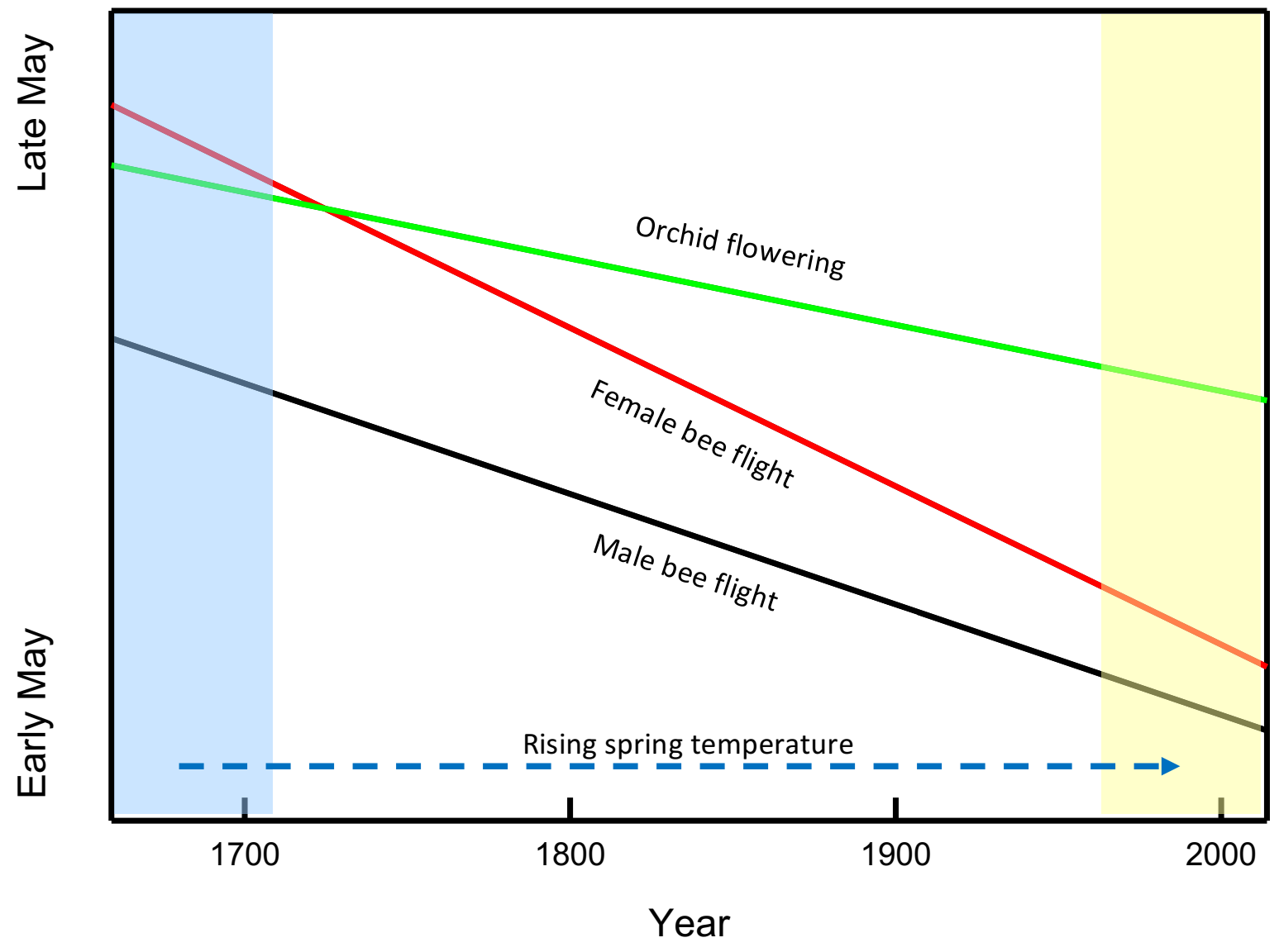




\section{Supplentary information in the online version}

Fig. S1. (a) Predicted peak flying dates of male Andrena nigroaenea between 1659 and 2014 $\left(y=124.87-0.03 x, r=0.293, r^{2}=0.086, P<0.0001, \mathrm{n}=354\right)$ and between 1970 and $2014(y$ $\left.=676.62-0.31 x, r=0.398, r^{2}=0.158, P<0.001, \mathrm{n}=44\right)$. (b) Predicted peak flying dates of female Andrena nigroaenea between 1659 and $2014\left(y=152.78-0.043 x, r=0.315, r^{2}=\right.$ $0.099, P<0.0001, \mathrm{n}=354)$ and between 1970 and $2014\left(y=1087.91-0.513 x, r=0.505, r^{2}=\right.$ $0.255, P<0.0001, \mathrm{n}=44$ ). (c) Predicted peak flowering dates of Ophrys sphegodes between 1659 and $2014\left(y=109.665-0.018 x, r=0.315, r^{2}=0.099, P<0.0001, \mathrm{n}=354\right)$ and between 1970 and $2014\left(y=493.67-0.211 x, r=0.505, r^{2}=0.255, P<0.0001, \mathrm{n}=44\right)$. The graphs for female flight date and orchid flowering date are similar in form because variation in timing of both is predicted using the same temperature measurement (mean temperature from March - May). The amplitude of variation in female flight time is approximately 2.5 times greater than that in flowering time. Times to flying and flowering are reported as days after March 1.

Fig. S1a

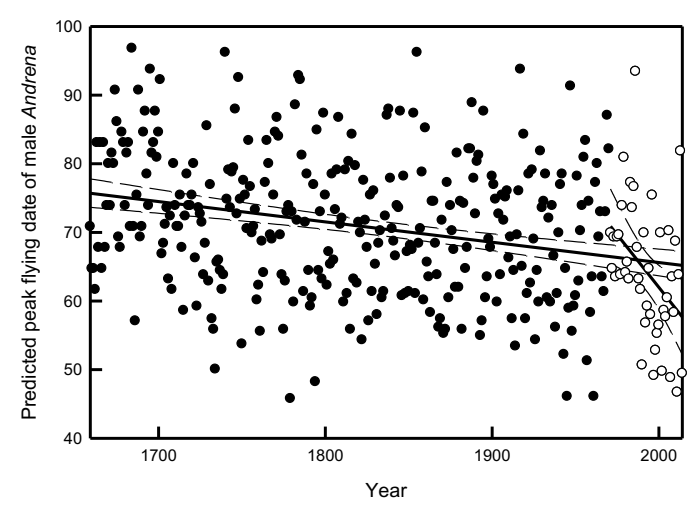


Fig. S1b

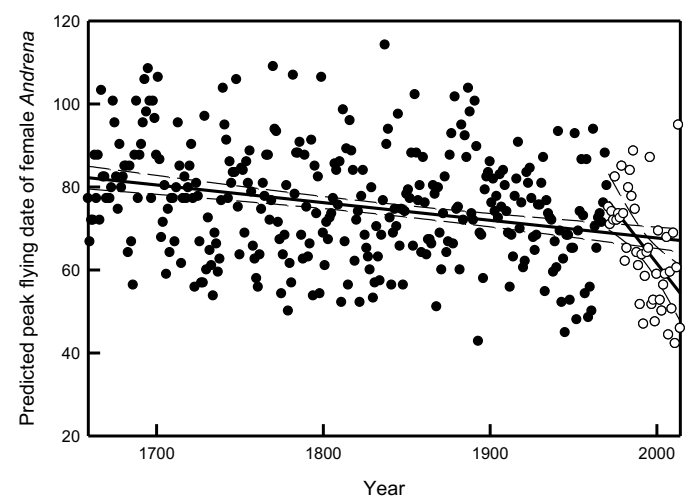

Fig. S1c

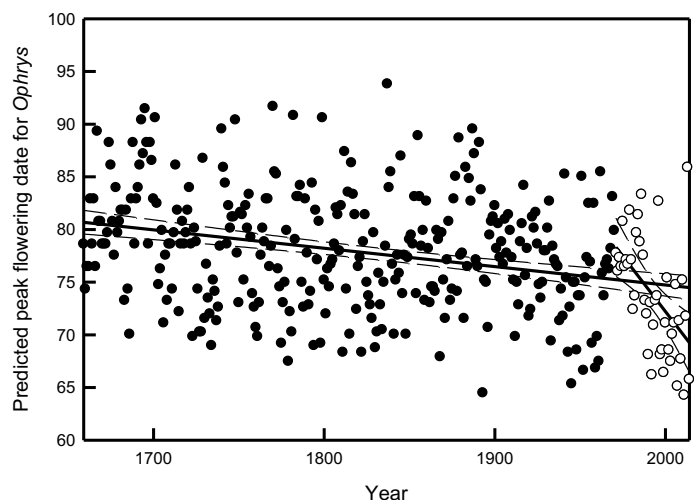

